\title{
A cross-curricular physical activity intervention to combat cardiovascular disease risk factors in II-14 year olds: 'Activity Knowledge Circuit' Gareth Knox*1, Julien S Baker ${ }^{2}$, Bruce Davies ${ }^{3}$, Susan Faulkner4, Jaynie Rance ${ }^{5}$, Anwen Rees ${ }^{1}$, Kelly Morgan ${ }^{1}$ and Non Thomas ${ }^{6}$
}

\begin{abstract}
Address: ${ }^{1}$ Cardiff School of Sport, University of Wales Institute Cardiff, Cardiff, UK, ${ }^{2}$ Health and Exercise Sciences, School of Sciences, University of the West of Scotland, UK, ${ }^{3}$ Faculty of Health, Sport and Science, University of Glamorgan, Pontypridd, UK, ${ }^{4}$ Department of Psychology, Careers and Education, University of Glamorgan, Pontypridd, UK, ${ }^{5}$ School of Health Sciences, Swansea University, Swansea, UK and ${ }^{6}$ School of Human Sciences, Swansea University, Swansea, UK

Email: Gareth Knox* - gaknox@uwic.ac.uk; Julien S Baker - Julien.Baker@uws.ac.uk; Bruce Davies - bdavies1@glam.ac.uk; Susan Faulkner - sfaulkne@glam.ac.uk; Jaynie Rance - J.Y.Rance@swansea.ac.uk; Anwen Rees - anrees@uwic.ac.uk; Kelly Morgan - kelly_morgan1987@hotmail.co.uk; Non Thomas - N.E.Thomas@swansea.ac.uk

* Corresponding author
\end{abstract}

Published: 15 December 2009

BMC Public Health 2009, 9:466 doi: I0.1 I86/I47|-2458-9-466
Received: 10 September 2009

Accepted: 15 December 2009

This article is available from: http://www.biomedcentral.com/I47I-2458/9/466

(c) 2009 Knox et al; licensee BioMed Central Ltd.

This is an Open Access article distributed under the terms of the Creative Commons Attribution License (http://creativecommons.org/licenses/by/2.0), which permits unrestricted use, distribution, and reproduction in any medium, provided the original work is properly cited.

\begin{abstract}
Background: Cardiovascular disease is the leading cause of mortality worldwide. Risk factors associated with cardiovascular disease have been shown to track from childhood through to adulthood. Previous school-based physical activity interventions have demonstrated modest improvements to cardiovascular disease risk factors by implementing extra-curricular activities or improving current physical education curriculum. Few have attempted to increase physical activity in class-room taught curriculum subjects. This study will outline a school-based cross-curricular physical activity intervention to combat cardiovascular disease risk factors in $1 \mathrm{I}-14$ year old children.
\end{abstract}

Method/Design: A South Wales Valley school of low socio-economic status has been selected to take part. Participants from year eight (12-13 years) are to be assigned to an intervention group, with maturation-matched participants from years seven ( $1 \mathrm{I}-12$ years) and nine (I3-14 years) assigned to a control group. A cross-curricular physical activity intervention will be implemented to increase activity by two hours a week for 18 weeks. Participants will briskly walk $3200 \mathrm{~m}$ twice weekly during curriculum lessons ( 60 minutes duration). With the exception of physical education, all curriculum subjects will participate, with each subject delivering four intervention lessons. The intervention will be performed outdoors and on school premises. An indoor course of equal distance will be used during adverse weather conditions. Cardiovascular disease risk factors will be measured pre- and post-intervention for intervention and control groups. These will take place during physical education lessons and will include measures of stature, mass, waist, hip, and neck circumferences, together with skinfold measure's taken at four sites. Blood pressure will be measured, and fitness status assessed via the $20 \mathrm{~m}$ multi-stage fitness test. Questionnaires will be used to determine activity behaviour (physical activity questionnaire for adolescence), diet (seven day food diary) and maturation status. Fasting blood variables will include total cholesterol, lowdensity lipoprotein cholesterol, high density lipoprotein cholesterol, triglycerides, insulin, glucose, 
high-sensitivity C-reactive protein, interleukin-6, adiponectin, and fibrinogen. Motivational variables and psychological well-being will be assessed by questionnaire.

Discussion: Our study may prove to be a cost effective strategy to increase school time physical activity to combat cardiovascular disease risk factors in children.

Trial Registration: [NCT00998478]

\section{Background}

Cardiovascular disease (CVD) is the leading cause of mortality worldwide [1]. In 2005 there was a reported 17.5 million deaths related to the disease, representing $30 \%$ of the global population [2]. Risk factors for CVD including obesity, blood pressure, blood lipids and lipoproteins have shown to track from childhood through to adulthood $[3,4]$. Metabolic syndrome (MetS) is the co-existence of multiple risk factors including hyperinsulinaemia, glucose intolerance, hypertension, decreased levels of high-density lipoprotein cholesterol (HDL-C) and elevated triglycerides (TG) [5]. At least one MetS risk factor was evident in one third of children (12-19 years) from the Third National Health and Nutritional Survey [6]; whereas one in ten was diagnosed with the syndrome itself when using the National Cholesterol Education Programme - Third Adult Treatment Panel definition. The prevalence of overweight and obesity for children (4-18 years) in the UK is reported to be 15 and $4 \%$ respectively [7]. Furthermore, in comparison to England (2.9\%) obesity was more prevalent for those living in Scotland (7.6\%) and Wales (6.5\%).

For many, overweight and obesity is the result of the combined effect of excess energy consumption and inadequate physical activity (PA) [8]. Previously, for children and adolescents PA has correlated negatively with body fatness and insulin resistance [9-11]. Conclusions regarding associations with blood lipids and lipoproteins are less clear. Although a recent meta-analysis reported no effect of aerobic exercise on non-high-density lipoprotein cholesterol, further studies are warranted [12]. Despite this, significant inverse relationships between PA and metabolic risk scores have recently been reported $[13,14]$, highlighting the importance of PA on childhood health. Schools are thought to be the ideal setting to implement PA interventions to combat CVD risk factors, with access to large populations from a variety of social classes, coinciding with a monitoring structure already in place $[15,16]$.

The association between psychosocial variables and obesity is complex. Research findings in this area indicate that there is a relationship between depression in youth and subsequent obesity $[17,18]$. The stigma attached to being overweight may affect peer relationships and may result in children and adolescents feeling less able to participate in
PA and more likely to suffer from psychological distress $[19,20]$.

The impact of PA on psychological health and well being has been noted for some years. Biddle et al. [21] reported that PA was associated with reduced levels of anxiety and depression and improved self-esteem, mood and cognitive function. In addition, epidemiological evidence suggests that PA is associated with a decreased risk of developing depression [22]. Exercise programmes have consistently been found to be as effective in reducing levels of depression in adult samples as a variety of standard psychotherapeutic treatments [23].

The relationship between PA and psychological wellbeing needs further investigation. Physical activity can have a positive effect on self-esteem and physically active children tend to suffer from fewer mental health problems [24]. In a review of PA in children and adolescents, Biddle et al. [25] suggest that a lack of PA in children has been associated with a number of psychosocial variables and perceived barriers. Positive effects on self-esteem are evident for all people participating in PA however the impact on self-perceptions is particularly strong for children [26]. A different pattern of psychosocial variables seems to be important for adolescents including perceived competence, and achievement orientation.

Previous school-based interventions targeting both children and adolescents have demonstrated modest improvements to CVD risk factors, including obesity, insulin resistance, blood pressure, and blood lipids [15,27-29]. Many of these school-based interventions have also looked to improve diet. Most school-based PA interventions have looked to improve physical education (PE) lessons or to provide extra-curricular activities $[15,30,31]$; few studies have sought to increase PA levels by integrating exercise into what would normally be classroom delivered subjects.

Recently an intervention by Reed et al. [32] used a whole school approach targeting six action zones to increase elementary school children's (9-11 years) PA. The only prescriptive component was to introduce three 15-minute periods per week of classroom PA. This allowed participants to carry out activities including skipping, dancing 
and resistance exercises. Sixteen months into the programme, improvements in aerobic fitness and blood pressure were evident, but no effect was observed for blood lipids, apolipoprotein B, C-reactive protein, and fibrinogen. Despite detail pertaining to the duration of time provided for participants to perform PA, there was no information regarding the amount of actual PA performed. It is evident that more population-based prevention programs are needed [33]. Targeting class-room based curriculum subjects with an increase in PA, may display favourable outcomes in child CVD risk status.

\section{Method/Design Objectives}

This study aims to implement an 18-week school-based cross-curricular exercise intervention to improve CVD risk status, psychological well-being, and motivation to exercise in 12 to 14 year old children.

\section{Primary Objectives}

1. Reduce measures of obesity including body mass index (BMI), waist, hip, and neck circumferences, and total skinfold thickness.

\section{Reduce systolic and diastolic blood pressure.}

3. Improve aerobic fitness profiles and increase PA behaviour.

4. Improve blood lipid profiles and lower levels of plasma inflammatory markers.

5. To assess the impact of motivation to exercise on physiological and psychological outcomes following the cross-curricular intervention

6. To influence psychological well being (mood and negative affect), self concept, and cognitive performance in an intervention group compared with a control.

\section{Secondary Objectives}

Determine associations between CVD risk factors measured at baseline in 11-14 year old children and adolescents. To investigate the relationships between specific physiological and psychological changes between and within participants.

\section{Participants}

A South Wales Valley school of low socio-economic status (SES) has been selected to take part. Free school meal eligibility was used to ascertain a valid measure of SES [34]. Of all 11-16 year olds attending the school, a reported $28 \%$ are eligible for free school meals which is above the unitary authority average of 25\% [35]. Following an explanation of the study's aim to the school's headmaster, gatekeeper consent has been granted for participants from years seven (11-12 years), eight (12-13 years), and nine (13-14 years) to take part. Participants from year eight will be assigned to an exercise intervention; maturation matched participants from years seven and nine will form a control group. A member of the research team will outline the study to all children from years seven, eight, and nine during the relevant school assemblies. This will be followed by the distribution of appropriate information sheets together with consent forms. Written consent and assent will be required from both parent/guardian and child respectively for participation in the study. A favourable opinion was provided by the Dyfed Powys Research Ethics Committee for this project.

\section{Data Analysis}

A quasi-experimental design will be used to compare differences in measured outcomes between pupils assigned to an intervention or control group. Initially, baseline data will be used to perform pearson's product moment correlation coefficients, followed by multiple regression analysis to estimate the significance of selected predictors on CVD risk factors. Dependant t-tests will be employed to assess differences between measures taken at baseline and post-intervention with independent t-tests utilised to detect differences in variables between groups. Statistical significance will be set at $P \leq 0.05$. Power calculations revealed that 100 participants from the exercise group and 60 participants from the control were required to achieve $80 \%$ power.

\section{Intervention}

In addition to regular PE lessons (60 min duration), this intervention will aim to increase PA by an additional two hours per week, for 18 weeks. A cross-curricular PA intervention involving all academic subjects termed the 'Activity Knowledge Circuit' will be followed by year eight pupils. These participants will complete 3,200 m of brisk walking during a 60 mins subject (normally classroom based) lesson, where a metronome set at 130 beats per minute will provide a walking speed. Initial pilot work carried out suggests that walking at this intensity for 3,200 m elicits relative oxygen uptake values of $17.0 \pm 1.3 \mathrm{ml}$ ${ }^{1} \mathrm{~kg}^{-1} \mathrm{~min}^{-1}$. Following 18 -weeks, performing two intervention lessons per week, it is calculated that energy expenditure will equate to $4039 \pm 1387 \mathrm{kcal}$, leading to a predicted weight loss of $1.2 \pm 0.4$ lbs, without accounting for confounding variables.

Each intervention lesson will be supervised by a subject teacher, and researcher or member of the PE department to ensure participants walk at the correct speed. Each participant will perform two intervention lessons per week, in addition to two regular PE lessons, thereby increasing 
activity by two hours a week. Intervention lessons will be integrated into the regular school timetable, and no more than four intervention lessons will be delivered by each curriculum subject during the 18-week period. Short tasks, in line with current curriculum, will be provided by subject teachers for participants to complete at stations set every 400 or $800 \mathrm{~m}$. Participants will therefore, still follow national curriculum whilst exercising at the same time. Tasks are to be designed by teachers to last no longer than 60 seconds at each station. Physical Education lessons are to be implemented as usual.

Normally, all intervention classes will be performed outside on school premises on a pre-determined course. In adverse weather conditions, a course of equal distance has been arranged undercover, again on school premises, so preventing any disruption to the intervention schedule. Participants will wear school uniform whilst taking part, but suitable footwear will be advised. Registers are to be kept during each intervention-led lesson to monitor absentees.

\section{Measurements}

All measurements will be performed pre- and post-intervention for both intervention and control groups (Figure 1). These are to be carried out by trained, gender specific individuals during PE lessons and on school premises to ensure minimal disruption to the curriculum. Individuals performing measurements will be CRB checked prior to data collection. Pre- and post-intervention measurements will be voluntary and last no longer than three weeks. Participants will be informed that they may withdraw at any point and that all information collected would be confidential.

\section{Anthropometrics}

Stature will be measured to the nearest millimetre using a portable stadiometer (Seca Stadiometer, Cardiokinetics Ltd. Salford, UK). Body mass will be measured to the nearest tenth of a kilogram using balance beam scales (Seca 710 Health Scales, Cardiokinetics Ltd. Salford, UK). Body mass index may then be calculated as body mass divided by stature squared and expressed as kilograms per metre squared. Waist and hip circumferences are to be measured whilst in a standing position using anthropometric tape. Waist circumference will be obtained laterally, midway between the lowest point of the rib cage and iliac crest, and measured at the end of a gentle expiration. Hip circumference will be taken at the widest point over the buttocks. Skinfold measurements obtained by callipers (Harpenden Skinfold Callipers, British Indicators, West Sussex, UK), will be measured at the biceps, triceps, subscapular, and suprailiac sites according to standard techniques [36]. A third skinfold measurement will be taken if the first two measurements differ by more than $1.0 \mathrm{~mm}$.
Summation of all four skinfolds will provide total skinfold thickness (TSF).

\section{Blood Pressure}

Blood pressure measurements will be performed using an automated blood pressure monitor (Dinamap XL Automatic Blood Pressure Monitor, Critikron Inc., Tampa, FL) following ten minutes of participants sitting quietly. The cuff will be positioned on the upper left arm and three measurements will be obtained with an average of the second and third used for data analysis [37]. Measures of systolic and diastolic blood pressure are to be recorded.

\section{Aerobic Fitness Profile}

Physical fitness will be estimated indirectly according to the participants' performance on the $20 \mathrm{~m}$ shuttle run (20MST) [38]. Each stage of the test is made up of several shuttle runs and the numbers of shuttles performed will be recorded. Higher shuttle scores will indicate higher levels of cardiovascular function. Testing will take place in the school's sports hall and consistent verbal encouragement will be given throughout. All participants will complete a prescribed warm up and cool down of light jogging and stretching. This test has previously been shown to be a valid assessment of maximal oxygen uptake in young individuals [39].

\section{Questionnaires}

The physical activity questionnaires for adolescents (PAQA) is to be used to report physical activity behaviour. This has previously been reported to be a valid and reliable measure of PA [40]. Each participant will record the amount of PA performed during the previous week by using a scale of 1-5; whereby 5 indicates high activity patterns and 1 represents low activity. Self-reported maturation status will be determined via questionnaire [41]. Participants will use recall to indicate their current stage of development. Self reported diet questionnaires will be provided for participants to complete at home. This includes a seven day food diary where participants record exactly what is consumed for breakfast, lunch, and dinner, as well as any snacks and drinks between meals. The diaries will be analysed for average daily kilojoules, percentage of total fat, saturated fat, carbohydrate, protein, and fibre by Health Options Ltd. (Health Options Ltd, Eastbourne, East Sussex, UK).

\section{Blood Sampling and Analysis}

Following an overnight fast, venous blood samples will be collected between 9.00 and 10.00 a.m. the following day. Participants will be required to assume a seated position for 30 minutes prior to sampling to control for plasma volume shifts [42]. Blood samples will be collected by qualified phlebotomists, and a health professional will be in attendance throughout. Breakfast will be provided to 


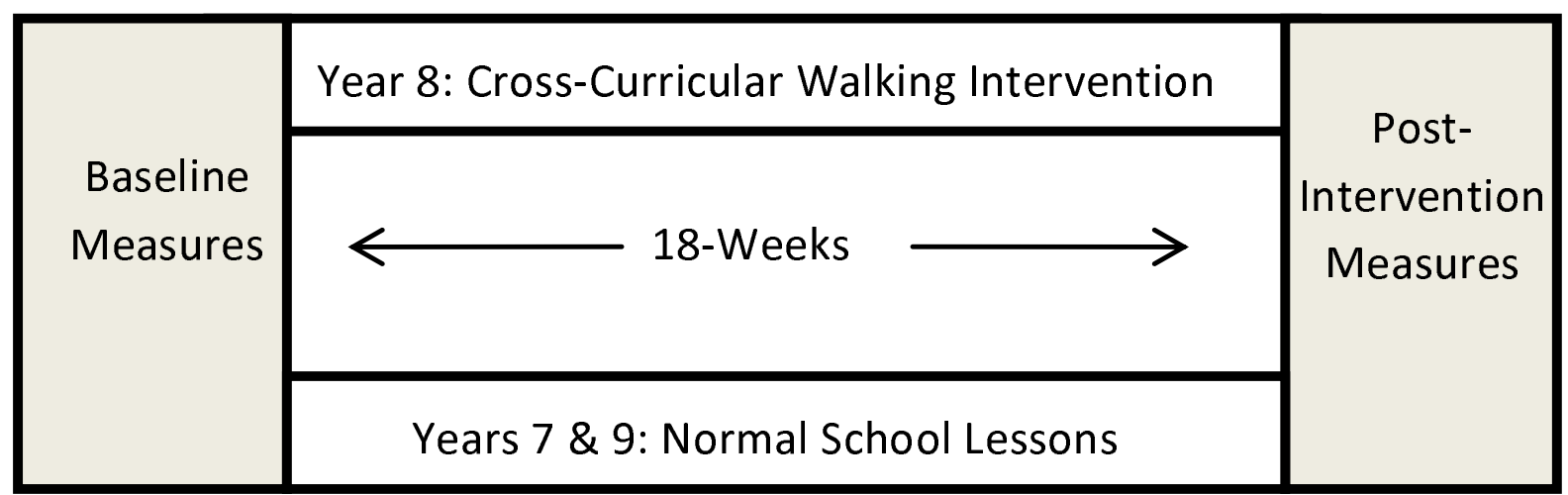

\section{Measurements}

\section{Anthropometrics}

Height.

Weight.

Waist, Hip, \& Neck

Circumferences.

Biceps, Triceps, Suprailiac,

\& Subscapular Skinfolds.

\section{Blood Pressure}

Systolic Blood Pressure.

Diastolic Blood Pressure.

\section{Cardio-respiratory Fitness}

$20 \mathrm{~m}$ Multi-stage Fitness Test.

\section{Questionnaires}

Physical Activity Questionnaire

for Adolescents.

Maturation Status .

Dietary Questionnaire.

\section{Fasting Blood Variables}

Total Cholesterol.

High-density Lipoprotein Cholesterol. Low-density Lipoprotein Cholesterol.

Triglycerides.

Insulin.

Glucose.

High-Sensitivity C-Reactive Protein. Interleukin-6.

Fibrinogen.

Adiponectin.

\section{Psychological Variables}

Motivation.

Well-being (Mood States).

Figure I

Study design including measurements. 
all participants immediately following sampling in the school canteen. Within two hours, all blood samples are to be transported to the laboratory and analysed immediately. Samples will be analysed for total cholesterol (TC), low-density lipoprotein cholesterol (LDL-C), HDL-C, TG, insulin, glucose, high-sensitivity C-reactive protein (hsCRP), interleukin-6 (IL-6), adiponectin (high molecular weight), and fibrinogen (Fg).

\section{Psychological Measures}

A number of psychosocial variables have been found to influence motivation to engage in PA, for example, readiness to change; self-efficacy and beliefs in ability; self-perception; goal orientation; enjoyment of activity. The aim of measuring motivation is to help develop strategies to increase the effectiveness of the intervention. One of the most enduring theoretical approaches to the study of motivation for PA is Self-Determination theory [43]. The measures selected are underpinned by this theoretical approach, and have all been well validated for use with the proposed sample:

Physical activity has been shown to reduce levels of anxiety and depression in the general population. Symptoms of anxiety and depression will be measured in the proposed sample by using well validated standardised instruments as detailed below:

\section{Motivation}

Readiness for change will be measured using five questions based on Kearney et al. [44]. Behavioural regulation in PA will be measured using the perceived locus of causality questionnaire (PLOC) [45]. The Task and Ego Orientation in Sport Questionnaire (TEOSQ) will be used to measure achievement orientation [46]. The Self Perception Profile for Adolescents will assess perceptions of competence including global self worth as well as perceptions of scholastic and athletic competence, physical appearance, social acceptance and behavioural conduct [47]. Beliefs in ability (self-efficacy) will be measured using the Conceptions of the Nature of Athletic Ability Questionnaire (CNAAQ-2) [48]. Enjoyment of PA will be measured using the Physical Activity Enjoyment Scale (PACES) [49]. These measures will be taken pre and post intervention to assess causal and moderating effects on outcomes.

\section{Psychological Well-being (Mood States)}

Anxiety will be measured using the State/Trait Anxiety Inventory for Children (STAI-CH) [50]. Depression will be measured using the Centre for Epidemiological Studies Depression Scale for Children (CES-DC) [51]. The d2 test of attention will be used to measure selective attention and mental concentration [52].

\section{Feedback}

Feedback to both participants and parents/guardians will be provided following completion of post-intervention measurements. Providing feedback prior to the intervention may lead to alterations in lifestyles leading to a confounding effect. Feedback is to be provided on an individual and group basis. Individuals will be provided with pre- and post-intervention results, together with an explanation of results accompanied by suitable advice to modify lifestyle. Group feedback will be provided to the schools headmaster, and any abnormal findings are to be reported to participants' general practitioner.

\section{Discussion}

Previous school-based PA interventions resulting in modest improvements to CVD risk status have typically been improvements to current PE curriculum or the introduction of extra-curricular sessions [15,30,31]. Our intervention will increase PA by an additional two hours per week by introducing brisk walking into curriculum subjects. This may be a cost effective strategy to increase PA in schools that could be implemented long term, targeting all children. By employing a cross-curricular intervention, PA becomes part of participants' school routine, therefore reducing the option to withdraw unless injury or illness prevents them from taking part.

Although most school-based PA intervention studies have focused on improving obesity, positive responses to other cardiovascular risk factors have been reported. Significantly lower systolic and diastolic blood pressures were reported by Bayne-Smith et al. [28], however, only girls were studied and the intervention included lectures on nutrition and behaviour modification as well as vigorous PA. Positive responses to BMI and serum lipid levels were reported by Manios et al. [27] by introducing an intervention to improve both diet and PA. Our study design will highlight the effect of introducing two hours of brisk walking a week on traditional CVD risk factors including obesity, blood lipid and lipoprotein profile and blood pressure. Evidence will also be provided on the effect of walking on other CVD risk factors including hs-CRP, IL-6, adiponectin, and Fg. Little information exists with regards to the effects of school-based exercise interventions on such variables.

The inclusion of motivational and psychological variables addresses a gap in research of this nature. It is clear that psychosocial factors are important in understanding the reason why young people engage (or fail to engage) with exercise programs. Furthermore, the psychological outcomes of participation (possible improvements in mood and concentration) and the extent to which they act as motivators for participation should be considered. If it can be established that increased participation in exercise 
has a notable effect on motivation to participate in exercise and psychological well-being together with improvements in CVD risk status, this may lead to long-term implications such as improved peer relations and school performance.

One of the main limitations to this study includes use of non-randomised sampling, whereby participants from year eight are to be selected to participate in the intervention, with participants from both years seven and nine making up the control group. This is unavoidable due to the manner in which the intervention is to be implemented. Randomly selecting participants from years seven, eight, and nine would lead to children of the same class being divided into intervention and control groups. This would cause too great a disruption to the school's regular curriculum, as well as requiring additional teachers. We considered assigning a whole year group to the intervention, and including maturation matched participants from other year groups as controls, is deemed more practicable. Future studies may look to involve a greater number of schools, allowing the opportunity to randomly assign different schools to an intervention or control group.

\section{Competing interests}

The authors declare that they have no competing interests.

\section{Authors' contributions}

NT, GK, SF and JR designed and wrote the original proposal. This has been modified and adapted by JB, BD, AR and KM. All authors have read and approved the final manuscript.

\section{Acknowledgements}

This work has been funded by a grant from the Sports Council Wales. The authors would like to express their thanks to the pupils and staff of Porth County Community School, Rhondda Cynon Taff.

\section{References}

I. Bonow RO, Smaha LA, Smith SC, Mensah GA, Lenfant C: World Heart Day 2002: The international burden of cardiovascular disease: Responding to the emerging global epidemic. Circulation 2002, I06: 1602-1605.

2. Preventing chronic diseases a vital investment. World Health Organization. Switzerland; 2005.

3. Twisk JWR, Kemper HCG, van Mechelen W, Post GB: Tracking of risk factors for coronary heart disease over a I4-year period. American Journal of Epidemiology 1997, I 45:888-898.

4. Eisenmann JC, Welk GJ, Wickel EE, Blair SN: Stability of variables associated with the metabolic syndrome from adolescence to adulthood: The Aerobics Center Longitudinal Study. American Journal of Human Biology 2004, I 6:690-696.

5. Reaven GM: Role of insulin resistance in human disease. Diabetes 1988, 37: |495-1507.

6. De Ferranti SD, Gauvreau K, Ludwig DS, Neufeld EJ, Newburger JW, Rifai N: Prevalence of the metabolic syndrome in American adolescents. Circulation 2004, I I 0:2494-2497.

7. Jebb SA, Rennie KL, Cole TJ: Prevalence of overweight and obesity among young people in Great Britain. Public Health Nutrition 2003, 7:46|-465.
8. Doak CM, Visscher TLS, Renders CM, Seidell JC: The prevention of overweight and obesity in children and adolescents. Obesity Reviews 2006, 7:III-I36.

9. Rowlands AV, Eston RG, Ingledew K: Relationship between activity levels, aerobic fitness, and body fat in 8- to 10 -yr-old children. Journal of Applied Physiology 1999, 86: | 428-1435.

10. Krekoukia M, Nassis GP, Psarra G, Skenderi K, Chrousos GP, Sidossis LS: Elevated total and central adiposity and low physical activity are associated with insulin resistance in children. Metabolism Clinical and Experimental 2007, 56:206-2I3.

II. Rizzo NS, Ruiz JR, Oja L, Veidebaum T, Sjostrom M: Associations between physical activity, body fat, and insulin resistance (homeostatic model assessment) in adolescents: The European Youth Heart Study. The American Journal of Clinical Nutrition 2008, 87:586-592.

12. Kelley GA, Kelley KS: Effects of aerobic exercise on Non-HDL$C$ in children and adolescents: $A$ meta-analysis of randomized controlled trials. Progress in Cardiovascular Nursing 2008, 23:128-132.

13. Platat C, Wagner A, Klump T, Schweitzer B, Simon C: Relationships of physical activity with metabolic syndrome features and low-grade inflammation in adolescents. Diabetologia 2006, 49:2078-2085.

14. Ekelund U, Anderssen SA, Froberg K, Sardinha LB, Andersen LB, Brage $S$ : Independent associations of physical activity and cardiorespiratory fitness with metabolic risk factors in children: The European Youth Heart Study. Diabetologia 2007, 50:1832-1840.

15. Warren JM, Henry CJK, Lightowler HJ, Bradshaw SM, Perwaiz S: Evaluation of a pilot school programme aimed at the prevention of obesity in children. Health Promotion International 2003, I 8:287-296.

16. Zahner L, Puder JJ, Roth R, Schmid M, Guldimann R, Puhse U, Knopfli M, Braun-Fahrlander C, Marti B, Kriemler S: A school-based physical activity program to improve health and fitness in children aged 6-13 years ("Kinder-Sportstudie KISS"): Study design of a randomised controlled trial. BMC Public Health 2006, 6:147.

17. Pine DS, Goldstein RB, Wolk S, Weissman MM: The association between childhood depression and adulthood body mass index. Pediatrics 2001, 107:1049-1056.

18. Goodman E, Whitaker RC: A Prospective Study of the Role of Depression in the Development and Persistence of Adolescent Obesity. Pediatrics 2002, I I 0:497-504.

19. Eisenberg ME, Neumark-Sztainer D, Story M: Associations of weight-based teasing and emotional well being among adolescents. Arch Pediatr Adolsec Med 2003, 1 57:733-738.

20. Faith MS, Saelens BE, Wilfley DE, Allison DB: Behavioural treatment of childhood and adolescent obesity: Current status, challenges, and future directions. In Body image, eating disorders, and obesity in youth Edited by: Thompson JK, Smolak L. Washington DC: American Psychological Association; 200 I:3 I 3-340.

21. Biddle SJH, Fox KR, Boutcher SH: Physical Activity and Psychological wellbeing London: Routledge; 2000.

22. Mutrie N: The relationship between physical activity and clinically defined depression. In Physical Activity and Psychological wellbeing Edited by: Biddle SJH, Fox KR, Boutcher SH. London: Routledge; 2000:46-62.

23. Biddle SJH, Mutrie N: Psychology of Physical Activity: Determinants, WellBeing and Interventions London: Routledge; $200 \mathrm{I}$.

24. Mutrie N, Parfitt G: Physical activity and its link with mental, social and moral health in young people. In Young and Active? Young people and Health-enhancing Physical Activity: Evidence and Implications Edited by: Biddle SJH, Cavill N, Sallis JF. London: Health Education Authority; 1998:49-68.

25. Biddle SJH, Gorley T, Stensel D: Health Enhancing physical activity and sedentary behaviour in children and adolescents. Journal of Sports Sciences 2004, 22:679-70I.

26. Fox KR: The effects of exercise on self-perceptions and selfesteem. In Physical Activity and Psychological Well-Being Edited by: Biddle SJH, Fox KR, Boutcher SH. London: Routledge; 2000:88-I 17.

27. Manios Y, Moschandreas J, Hatzis C, Kafatos A: Evaluation of a health and nutrition education program in primary school children of Crete over a three-year period. Preventive Medicine 1999, 28:149-159. 
28. Bayne-Smith M, Fardy PS, Azzollini A, Magel J, Schmitz KH, Agin D: Improvements in heart health behaviours and reduction in coronary artery disease risk factors in urban teenage girls through a school-based intervention. The PATH program. American Journal of Public Health 2004, 94: I538-I543.

29. Carrel AL, Clark RR, Peterson SE, Nemeth BA, Sullivan J, Allen DB: Improvements of fitness, body composition, and insulin sensitivity in overweight children in a school-based exercise program. Arch Pediatr Adolesc Med 2005, I 59:963-968.

30. Sallis JF, McKenzie TL, Alcaraz JE, Kolody B, Hovell MF, Nader PR: Effects of physical education on adiposity in children. Annals New York Academy of Sciences 1993, 699:127-136.

31. Robinson TN, Kilen JD, Kraemer HC, Wilson DM, Matheson DM Haskell WL, Pruitt LA, Powell TM, Owens AS, Thompson NS, FlintMoore NM, Oavis G], Emig KA, Brown RT, Rochon J, Green S, Varady $A$ : Dance and reducing television viewing to prevent weight gain in African-American girls: The Stanford GEMS pilot study. Ethnicity and Disease 2003, I 3(Suppl I):65-77.

32. Reed KE, Warburton DER, Macdonald HM, Naylor PJ, McKay HA: Action schools! BC: A school-based physical activity intervention designed to decrease cardiovascular disease risk factors in children. Preventive Medicine 2008, 46:525-53I.

33. Sharma M: School-based interventions for childhood and adolescent obesity. Obesity Reviews 2006, 7:261-269.

34. Shuttleworth I: The relationship between social deprivation as measured by individual free school meal eligibility and educational attainment at GCSE in Northern Ireland: A preliminary investigation. British Educational Research Journal 1995, 21:487-504.

35. Report on the inspection under section 10 of the school inspection act 1996. Office of her Majesty's Chief Inspector of Schools in Wales. Cardiff 2003.

36. Weiner JS, Laurie JA: Practical Human Biology London: Academic Press; 1981.

37. Paradis G, Lambert M, O'Loughlin J, Lavallee C, Aubin J, Delvin E, Levy $E$, Hanley JA: Blood pressure and adiposity in children and adolescents. Circulation 2004, I I 0:1832-1838.

38. Leger LA, Mercier D, Gadoury C, Lambert J: The multistage 20 metre shuttle run test for aerobic fitness. Journal of Sports Science 1988, 6:93-101.

39. Liu NY-S, Plowman SA, Looney MA: The reliability and validity of the 20-meter shuttle test in American students 12 to 15 years old. Research Quarterly in Exercise and Sports 1992, 63:360-365.

40. Janz KF, Lutuchy EM, Wenthe P, Levy SM: Measuring activity in children and adolescents using self-report: PAQ-C and PAQA. Medicine and Science in Sport and Exercise 2008, 40:767-772.

41. Tanner J: Growth at adolescence Oxford: Blackwell; 1962.

42. Pronk NP: Short term effects of exercise on plasma lipids and lipoproteins in humans. Sports Medicine 1993, 16:431-448.

43. Deci EL, Ryan RM: Intrinsic motivation and self-determination in human behaviour. New York 1985.

44. Kearney JM, de Graff C, Damkjaer S, Engstrom LM: Stages of change towards physical activity in a nationally representative sample in the European Union. Public Health Nutrition 1999, 2:I15-124.

45. Goudas M, Biddle S, Fox K: Perceived locus of causality, goal orientations, and perceived competence in school physical education classes. British Journal of Educational Psychology 1994, 64:453-463.

46. Duda JL, Whitehead J: Measurement of goal perspectives in the physical domain. In Advances in sport and exercise psychology measurement Edited by: Duda JL. Morgantown, WV: Fitness Information Technology; 1998:21-48.

47. Harter S: Self-perception profile for adolescents Denver, CO: University of Denver Press; 1988.

48. Wang $\mathrm{CKJ}$, Biddle SJH: Young people's motivational profiles in physical activity: A cluster analysis. Journal of Sport and Exercise Psychology 2001, 23: I-22.

49. Kendzierski D, DeCarlo KL: Physical activity enjoyment scale: two validation studies. Journal of Sport and Exercise Psychology 1999, I 3:50-64.

50. Speilberger CD: Preliminary test manual for the State-Trait Anxiety Inventory for Children Palo Alto, CA: Consulting Psychology Press; 1973.

51. Faulstich ME, Carey MP, Ruggiero L, Enyart P, Gresham F: Assessment of depression in childhood and adolescence: an evaluation of the centre for Epidemiological Studies Depression
Scale for Children (CES-DC). American Journal of Psychiatry 1986, 143: I024-I027.

52. Brickenkamp R, Zillmer E: The d2 Test of Attention I st US edition. Seattle, WA: Hogrefe \& Huber Publishers; 1998.

\section{Pre-publication history}

The pre-publication history for this paper can be accessed here:

http://www.biomedcentral.com/1471-2458/9/466/pre pub
Publish with Bio Med Central and every scientist can read your work free of charge

"BioMed Central will be the most significant development for disseminating the results of biomedical research in our lifetime. "

Sir Paul Nurse, Cancer Research UK

Your research papers will be:

- available free of charge to the entire biomedical community

- peer reviewed and published immediately upon acceptance

- cited in PubMed and archived on PubMed Central

- yours - you keep the copyright

Submit your manuscript here:

http://www.biomedcentral.com/info/publishing_adv.asp
BioMedcentral 